\title{
A $\mathrm{Mg}^{2+}$-responding RNA That Controls the Expression of a $\mathrm{Mg}^{2+}$ Transporter
}

\author{
E.A. Groisman, M.J. Cromie, Y. Shi, * and T. Latifi \\ Department of Molecular Microbiology, Washington University School of Medicine, Howard Hughes \\ Medical Institute, St. Louis, Missouri 63110
}

\begin{abstract}
$\mathrm{Mg}^{2+}$ is the most abundant divalent cation in biological systems. It is required for ATP-mediated enzymatic reactions and as a stabilizer of ribosomes and membranes. The enteric bacterium Salmonella enterica serovar Typhimurium harbors three $\mathrm{Mg}^{2+}$ transporters and a regulatory system - termed $\mathrm{PhoP} / \mathrm{PhoQ}$ - whose activity is regulated by the extracytoplasmic levels of $\mathrm{Mg}^{2+}$. We have determined that expression of the PhoP-activated $\mathrm{Mg}^{2+}$ transporter MgtA is also controlled by its $5^{\prime}$-untranslated region (5'UTR). The 5'UTR of the $m g t A$ gene can adopt different stem-loop structures depending on the $\mathrm{Mg}^{2+}$ levels, which determine whether transcription reads through into the $m g t A$-coding region or stops within the $5^{\prime} \mathrm{UTR}$. This makes the $m g t A 5^{\prime} \mathrm{UTR}$ the first example of a cation-responding riboswitch. The initiation of $m g t A$ transcription responds to extracytoplasmic $\mathrm{Mg}^{2+}$, and its elongation into the coding region to cytoplasmic $\mathrm{Mg}^{2+}$, which provides a singular example where the same ligand is sensed in different cellular compartments to regulate disparate steps in gene transcription. The PhoP-activated $\mathrm{Mg}^{2+}$ transporter MgtB is also regulated by $\mathrm{Mg}^{2+}$ in a strain lacking the $\mathrm{Mg}^{2+}$ sensor PhoQ, suggesting the presence of additional $\mathrm{Mg}^{2+}$-responding devices.
\end{abstract}

All living organisms need $\mathrm{Mg}^{2+}$. This is because $\mathrm{Mg}^{2+}$ is an essential cofactor for all ATP-mediated enzymatic reactions and because $\mathrm{Mg}^{2+}$ helps maintain the stability of membranes as well as of certain macromolecular complexes such as the ribosome (Reinhart 1988). Therefore, cells must preserve physiological $\mathrm{Mg}^{2+}$ concentrations, which might not be the same in different subcellular compartments. To achieve this task, cells need to have the means to sense the levels of $\mathrm{Mg}^{2+}$ as well as the ability to modify the movement of this essential cation across biological membranes and/or from storage locations.

The gram-negative bacterium $S$. enterica serovar Typhimurium harbors a $\mathrm{Mg}^{2+}$-responding regulatory system (i.e., PhoP/PhoQ) (Groisman 2001), three $\mathrm{Mg}^{2+}$ transporters (i.e., CorA, MgtA, and MgtB) (for review, see Smith and Maguire 1998; Maguire 2006), and an integral membrane protein that is required for optimal growth in low $\mathrm{Mg}^{2+}$ (i.e., MgtC). The PhoP/PhoQ system consists of the PhoQ protein, a sensor for extracytoplasmic $\mathrm{Mg}^{2+}$, and the transcriptional regulator PhoP (Groisman 2001). When Salmonella experiences low $\mathrm{Mg}^{2+}$, the PhoQ protein promotes phosphorylation of the PhoP protein, which can then bind to its target promoters to modify gene transcription: PhoP-activated genes are turned on and PhoP-repressed genes are turned off. And when Salmonella faces high $\mathrm{Mg}^{2+}$, PhoQ promotes the unphosphorylated state of the PhoP protein, which is unable to bind to its target promoters and results in no transcription of PhoP-activated genes and derepression of PhoPrepressed genes (Soncini et al. 1996; Castelli et al. 2000;

*Present address: Arizona State University, The Biodesign Institute, Center for Infectious Diseases and Vaccinology, College of Liberal Arts and Sciences, School of Life Sciences, PO Box 874501, Tempe, Arizona 85287-4501.
Chamnongpol and Groisman 2000; Montagne et al. 2001; Chamnongpol et al. 2003).

The CorA protein can mediate both influx and efflux of $\mathrm{Mg}^{2+}$ and does not exhibit sequence similarity to the MgtA or MgtB proteins, which are $50 \%$ identical to one another and solely mediate $\mathrm{Mg}^{2+}$ influx (for review, see Smith and Maguire 1998; Maguire 2006). MgtA and MgtB also differ from CorA in that transcription of the $m g t A$ and $m g t B$ genes is directly regulated by the $\mathrm{PhoP}$ protein in response to extracytoplasmic $\mathrm{Mg}^{2+}$ sensed by the PhoQ protein (Soncini et al. 1996; Yamamoto et al. 2002; Zwir et al. 2005), whereas expression of CorA responds neither to $\mathrm{Mg}^{2+}$ nor to the PhoP/PhoQ system (Chamnongpol and Groisman 2002). Yet, the activity of the CorA transporter is enhanced in a phoP mutant by an unknown mechanism (Chamnongpol and Groisman 2002).

The PhoP/PhoQ system controls expression of about $3 \%$ of the genome. This includes not only the genes encoding the $\mathrm{Mg}^{2+}$ transporters MgtA and MgtB, but also the genes coding for products that modify the negatively charged residues in the lipopolysaccharide (i.e., LPS), which are neutralized primarily by $\mathrm{Mg}^{2+}$ (Groisman et al. 1997; Groisman 2001). The LPS is the dominant molecule in the outer leaflet of the outer membrane of Escherichia coli and Salmonella, and it has been estimated that more than one-third of the total $\mathrm{Mg}^{2+}$ content is located in the LPS (Groisman et al. 1997). The PhoP/PhoQ system and the MgtA and CorA transporters are widely distributed within the family Enterobacteriaceae (Smith and Maguire 1995; Blanc-Potard and Groisman 1997). This is in contrast to the sporadic distribution of the MgtB and MgtC proteins. This paper discusses the discovery, characterization, and function of the first example of an $\mathrm{Mg}^{2+}$ responding riboswitch, and how such RNA regulates cytoplasmic $\mathrm{Mg}^{2+}$ levels. 


\section{SECTION THEMES}

\section{The 5'UTR of the mgt $A$ mRNA Harbors a $\mathrm{Mg}^{2+}$-responding Regulatory Element}

PhoP* is a variant of the PhoP protein that can promote gene transcription in the absence of the $\mathrm{Mg}^{2+}$ sensor PhoQ (Chamnongpol and Groisman 2000). As expected, transcription of the PhoP-activated genes $p c g L$ and $p m r C$ did not respond to $\mathrm{Mg}^{2+}$ in a $p h o P^{*} \Delta p h o Q$ strain. In contrast, $\mathrm{Mg}^{2+}$ could still modulate $m g t A$ transcription in this strain. This suggested that an $\mathrm{Mg}^{2+}$-sensing system can regulate $m g t A$ expression independently of the $\mathrm{PhoP} / \mathrm{PhoQ}$ system. Consistent with this notion, Maguire's laboratory demonstrated that luciferase activity originating from a plasmid-borne $m g t A$-lux fusion was still up-regulated in media of very low $\mathrm{Mg}^{2+}$ in $p h o P$ and $p h o Q$ mutants (Tao et al. 1998).

The 5'UTR of the mgtA gene is 264 nucleotides long. Such a long $5^{\prime}$ UTR is unusual, raising the possibility that it might be involved in the regulation of $m g t A$ expression. Consistent with this notion, replacement of 100 nucleotides of the 5'UTR by an 84-bp "scar" sequence abolished $\mathrm{Mg}^{2+}$ regulation of $m g t A$ expression in the $p h o P^{*} \Delta p h o Q$ strain (Cromie et al. 2006). Moreover, $\mathrm{Mg}^{2+}$ regulated the production of $\beta$-galactosidase in a wild-type Salmonella strain harboring a plasmid containing the DNA sequence corresponding to the 264-bp mgtA 5'UTR region cloned between a derivative of the lac promoter and a promoterless lacZ gene (Cromie et al. 2006). These results demonstrated that the $5^{\prime} \mathrm{UTR}$ of $m g t A$ is necessary and sufficient for $\mathrm{Mg}^{2+}$ regulation.

\section{Analysis of the Potential Structures That May Be Adopted by the Phylogenetically Conserved $\boldsymbol{m g t} A$ 5'UTR Suggests a Possible Mechanism by Which mgt $A$ Expression Might Be Regulated}

The M-fold program predicted that the mgtA 5'UTR could form several stem-loop structures including two, designated $\mathrm{A}$ and $\mathrm{B}$, with predicted energies of -21.4 and $-13.2 \mathrm{kcal} / \mathrm{mole}$, respectively. Interestingly, an alternative stem-loop structure-termed $\mathrm{C}$-could be formed by pairing of sequences originating from the right arm of stem A and the region that separates stem-loops A and B with sequences in the left arm of stem-loop B. The resulting stem has a predicted energy of $-12.8 \mathrm{kcal} / \mathrm{mole}$, which is very similar to that predicted for stem-loop B (Fig. 1A).

Examination of the microbial genome databases revealed that in several enteric species, the $m g t A$ open reading frame is preceded by sequences that upon transcription could adopt stem-loop structures similar to those described above for the Salmonella mgtA 5'UTR. The high degree of primary and secondary structure conservation suggests that the possibility of forming the alternative stem-loop structures A plus B versus C is conserved in the mgtA 5'UTR of E. coli, Citrobacter rodentium, Klebsiella pneumoniae, Erwinia chrysanthemi, Serratia marcescens, and Yersinia enterocolitica (Fig. 1).

When wild-type Salmonella harbored a plasmid with the $m g t A 5^{\prime} \mathrm{UTR}$ region from $E$. coli $m g t A$ behind a derivative of the lac promoter and in front of a promoterless $l a c Z$ gene, $\beta$-galactosidase activity was 15 -fold higher in bacteria grown in low $\mathrm{Mg}^{2+}$ than in those grown in high $\mathrm{Mg}^{2+}$ (Cromie et al. 2006). Although this is lower than the 23-fold ratio exhibited by the isogenic strain with the plasmid harboring the Salmonella mgtA 5'UTR, these results demonstrate that the $E$. coli $m g t A 5^{\prime}$ UTR can also confer $\mathrm{Mg}^{2+}$ regulation.

Taken together with the fact that the mRNA levels for the 5'UTR and coding region of the Salmonella mgtA gene are differentially regulated by $\mathrm{Mg}^{2+}$ (Cromie et al. 2006), the analyses described above suggest a model by which $m g t A$ expression might be controlled. According to this model, the $m g t A 5^{\prime}$ UTR may adopt different stemloop structures, which would be determined by the cytoplasmic levels of $\mathrm{Mg}^{2+}$, and depending on which structure is formed (stem-loops A plus B vs. stem-loop C; Fig. 1A), transcription would stop within the $5^{\prime}$ UTR or continue into the $m g t A$-coding region. Genetic analysis suggested that formation of stem-loops A plus B is associated with $m g t A$ transcription not reaching the coding region and could be the structure favored in high $\mathrm{Mg}^{2+}$. In contrast, formation of stem-loop $\mathrm{C}$ would result in readthrough into the $m g t A$-coding region, which would be expected for a structure forming in low $\mathrm{Mg}^{2+}$. In sum, the 5'UTR of the $m g t A$ gene appears to use an attenuationlike mechanism (Landick et al. 1996; Henkin and Yanofsky 2002) to control $m g t A$ expression.

\section{$\mathrm{Mg}^{2+}$ Can Modify the Structure of the $m g t A 5^{\prime}$ UTR}

During the last few years, research carried out primarily by the Breaker, Nudler, and Henkin laboratories has demonstrated that the $5^{\prime}$ UTR of certain bacterial transcripts can bind specific metabolites including amino acids, nucleotides, and sugars (for reviews, see Winkler 2005; Winkler and Breaker 2005). Binding of such a metabolite alters the expression of the open reading frames that follow the $5^{\prime}$ UTR, which are typically involved in the biosynthesis or transport of the metabolite. Thus, when the levels of the metabolite build up in the cytoplasm of the bacterial cell, the 5'UTRs function as "riboswitches" that upon binding the metabolite, turn off expression of the biosynthetic or transport proteins promoting accumulation of the metabolite (Winkler 2005; Winkler and Breaker 2005).

If the $m g t A 5^{\prime} \mathrm{UTR}$ functions as an $\mathrm{Mg}^{2+}$-responding riboswitch, one would expect that (1) it should bind $\mathrm{Mg}^{2+}$, (2) $\mathrm{Mg}^{2+}$ binding should promote the formation of particular structures in the $5^{\prime}$ UTR thereby affecting $m g t A$ expression, and (3) favoring the formation of particular structures by mutation should be associated with expression/lack of expression independently of the $\mathrm{Mg}^{2+}$ concentration experienced by the bacterial cell.

Enzymatic and chemical probing of the mgtA 5'UTR demonstrated that $\mathrm{Mg}^{2+}$ can alter the structure of this RNA at several places and that the $5^{\prime}$ UTR can adopt secondary structures which are consistent with the model predicted by the $\mathrm{M}$-fold program (Fig. $1 \mathrm{~A}$ ). $\mathrm{Mg}^{2+}$ binding to the $m g t A 5^{\prime} \mathrm{UTR}$ was entirely expected given that $\mathrm{Mg}^{2+}$ has been known to bind to different classes of RNA molecules in different capacities (e.g., $\mathrm{Mg}^{2+}$ has a critical role in the 
A
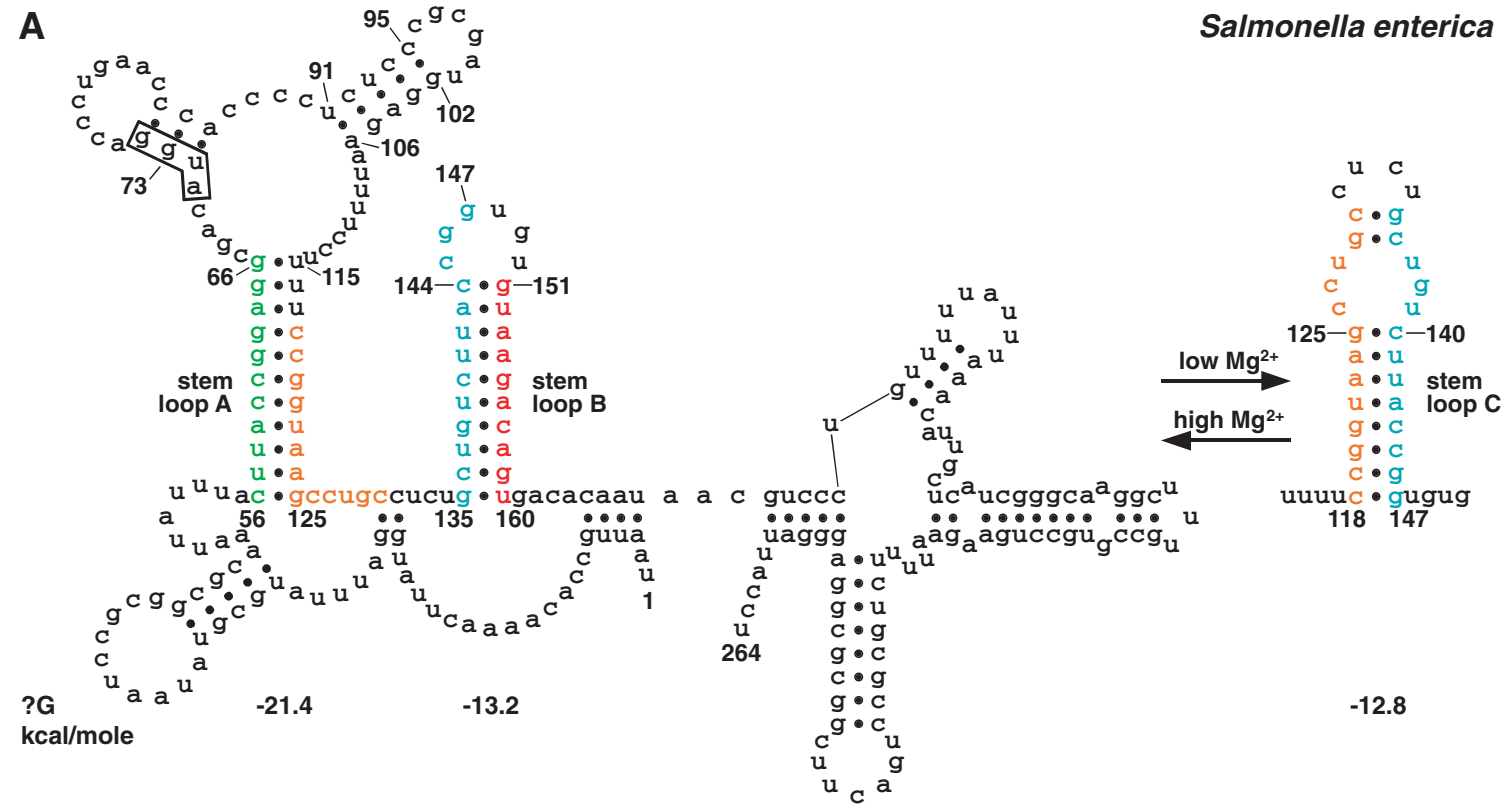

Salmonella enterica

B

Escherichia coli

C Citrobacter rodentium

D Klebsiella pneumoniae
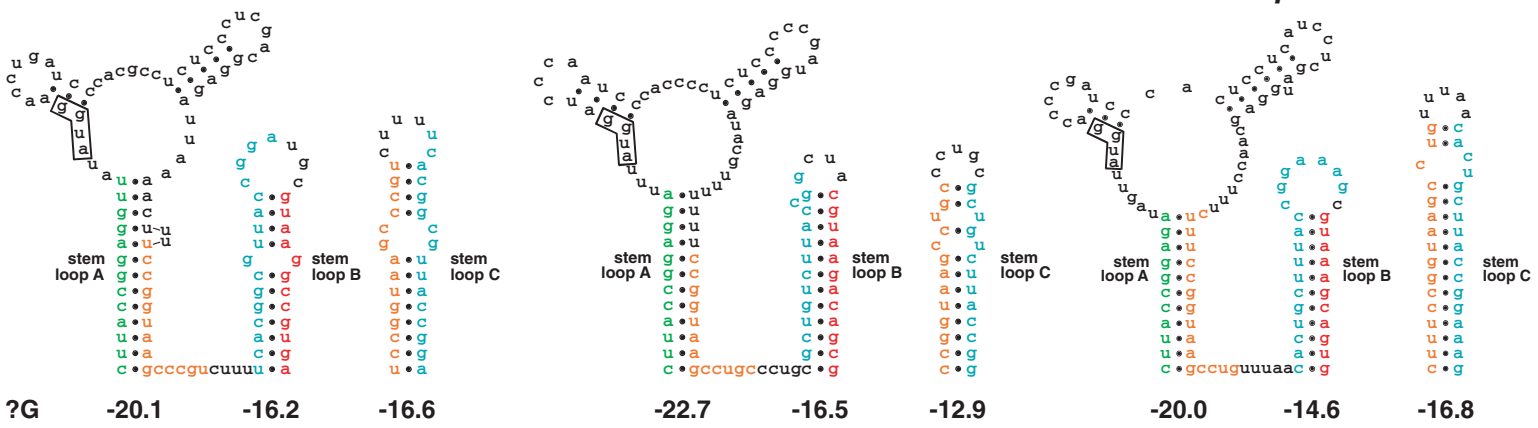

$\mathrm{kcal} / \mathrm{mole}$

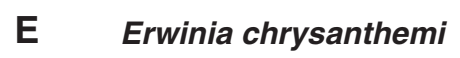

\section{G Yersinia enterocolitica}
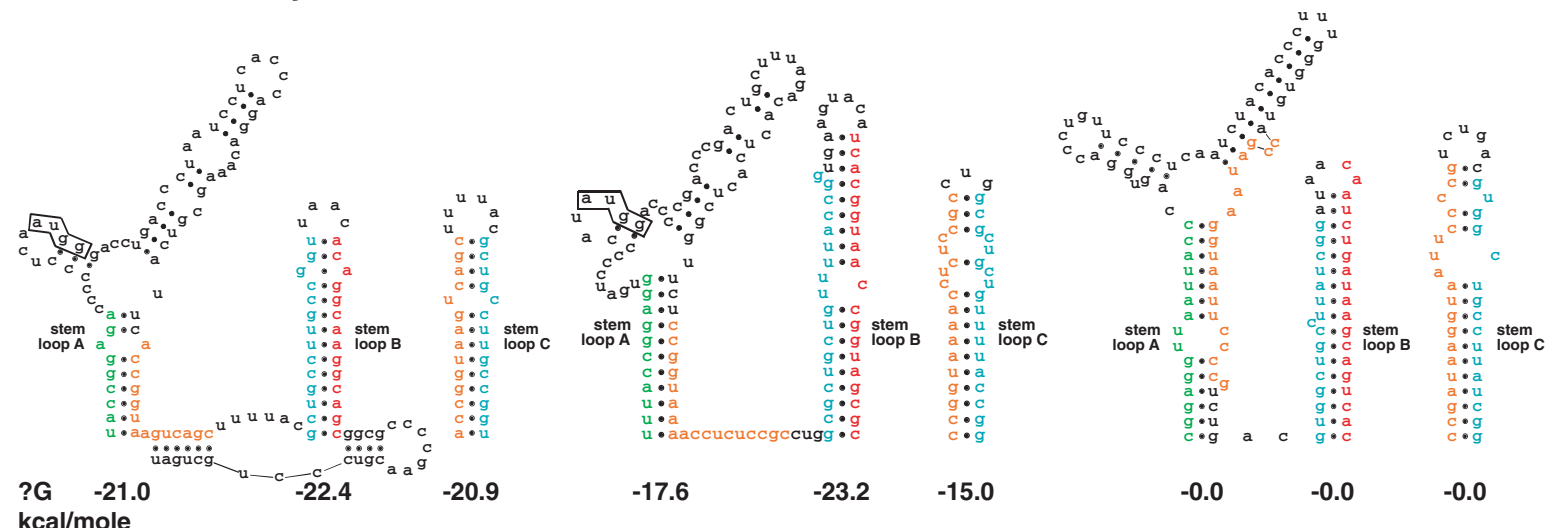

Figure 1. Predicted secondary structure of the phylogenetically conserved $m g t A 5^{\prime}$ UTR. (A) Schematic representation of the secondary structure of the 264-nucleotide $m g t A 5^{\prime}$ UTR as predicted by the M-fold program. (Left) Stem-loops A and B, which are postulated to form in high $\mathrm{Mg}^{2+}$; (right) stem-loop C, which is predicted to form in low $\mathrm{Mg}^{2+}$. Sequences in color represent regions involved in stem structures. The predicted energy for stem-loops A, B, and C is presented underneath. ( $B-G)$, Predicted stem-loop structures A, B, and C corresponding to the potential 5'UTRs for the mgtA gene from E. coli, C. rodentium, K. pneumoniae, E. chrysanthemi, S. marscescens, and Y. enterocolitica. Sequences in color represent regions involved in stem-loop structures. The predicted energy for the three stem-loops A, B, and C is presented underneath. Note conservation of AUGG sequence of loop A in all species but $Y$. enterocolitica and of the short stem-loop within loop A in S. enterica, E. coli, C. rodentium, and K. pneumoniae. Other conserved regions are shown in Cromie et al. (2006). (Reprinted, with permission, from Cromie et al. 2006 [C Elsevier].) 
structure and/or enzymatic activity of several ribozymes; Hanna and Doudna 2000). Thus, we focused our analysis on those regions of the $m g t A 5^{\prime} \mathrm{UTR}$ that were anticipated to be differentially affected by $\mathrm{Mg}^{2+}$ in ways that would affect gene expression. For example, G146 and G147 are predicted to be part of the loop in stem-loop B, which is anticipated to form in high $\mathrm{Mg}^{2+}$ but to be base-paired as part of stem $\mathrm{C}$ in low $\mathrm{Mg}^{2+}$ (Fig. 1A). By using RNase T1, which cleaves unpaired $\mathrm{G}$ residues, we detected more cleavage at both G146 and G147 at high $\mathrm{Mg}^{2+}$ than at low $\mathrm{Mg}^{2+}$, in agreement with the prediction. Likewise, G151 is predicted to be base-paired in high $\mathrm{Mg}^{2+}$ but unpaired in low $\mathrm{Mg}^{2+}$ (Fig. 1A), and that is what the $\mathrm{T} 1$ cleavage treatment showed (Cromie et al. 2006). On the other hand, $\mathrm{G} 149$ was cleaved to a similar extent in low and high $\mathrm{Mg}^{2+}$ as suggested by the model (Fig. 1A). Importantly, the low and high $\mathrm{Mg}^{2+}$ concentrations used in this experiment correspond to those around the physiological range (Froschauer et al. 2004).

\section{Formation of Stem-loop C Results in $m g t A$ Expression}

The genetic and biochemical data discussed above suggest that when stem-loop $\mathrm{C}$ is formed, the $m g t A$-coding region is transcribed. To test this model, we investigated the behavior of strains harboring mutant $m g t A 5^{\prime} \mathrm{UTR}$ in which the ability to form stem-loop $\mathrm{C}$ had been compromised. G120 is predicted to base-pair with C145 in the middle of stem $\mathrm{C}$ (Fig. 1A). Mutants with either the G120C or C145G single-nucleotide substitutions failed to express a reporter gene that was cloned behind the $5^{\prime} \mathrm{UTR}$ region (Cromie et al. 2006). This was true regardless of the $\mathrm{Mg}^{2+}$ concentration in which the organism was grown. On the other hand, the $\mathrm{G} 120 \mathrm{C} \mathrm{C145G}$ double mutant exhibited $\mathrm{Mg}^{2+}$-regulated expression of the reporter gene. This supports the notion that G120 can pair with C145 and that the ability to form stem $\mathrm{C}$ is necessary for $m g t A$ expression. Although C61 is predicted to base-pair with G120 in stem A, a strain with the $\mathrm{C} 61 \mathrm{G}$ substitution still expressed the reporter gene in a $\mathrm{Mg}^{2+}$-regulated fashion. However, instead of the tenfold ratio in transcription levels in low versus high $\mathrm{Mg}^{2+}$ exhibited by organisms with the wildtype $m g t A 5^{\prime} \mathrm{UTR}$, the ratio was less than fivefold. Thus, it would appear that the ability to form stem A is partially compromised in the $\mathrm{C} 61 \mathrm{G}$ mutant, which results in more than twofold higher levels of expression in high $\mathrm{Mg}^{2+}$, but not eliminated because base-stacking of $G$ residues may still favor formation of stem A. Finally, the RNAs corresponding to the G120C and C145G single mutants exhibited aberrant $\mathrm{T} 1$ cleavage patterns at positions away from the mutated nucleotides, indicative that these mutations can affect the formation of structures in other regions of the 5'UTR (Cromie et al. 2006).

\section{Looking for the $\mathrm{Mg}^{2+}$-sensing Domain of the $m g t A$ Riboswitch}

In their most straightforward form, riboswitches can be divided into two domains: an aptamer domain that is responsible for binding a specific ligand and an expression platform domain that is responsible for altering gene expression in response to ligand binding (Winkler and Breaker 2005). In fact, RNAs can be engineered to respond to particular ligands by mixing and matching RNAs of different origins (Kim et al. 2005; Muller et al. 2006). Then, which are the regions of the $5^{\prime} \mathrm{UTR}$ responsible for $\mathrm{Mg}^{2+}$ sensing and for modulating $m g t A$ expression upon $\mathrm{Mg}^{2+}$ binding?

As discussed above, the formation of stem-loops B and $\mathrm{C}$ is associated with lack of expression and expression of the $m g t A$ gene, respectively. Because the predicted $\Delta G$ s for these two stem-loop structures are very similar (Fig. 1A), we would hypothesize that a different part of the 5'UTR determines which of the two structures is formed and that such part of the $5^{\prime} \mathrm{UTR}$ is likely involved in $\mathrm{Mg}^{2+}$ sensing. Stem-loop $\mathrm{A}$ is a prime candidate for having this role because (1) this region is transcribed before stem-loops B and $\mathrm{C}$, and thus would be available to bind $\mathrm{Mg}^{2+}$ before the rest of the $5^{\prime} \mathrm{UTR}$ is made, and (2) it is conserved with other enteric species, and some of the conserved nucleotides are differentially cleaved by RNase T1 in the presence of $\mathrm{Mg}^{2+}$. We targeted for mutagenesis a short stem predicted to be present in the loop-A region and found that a mutant in which the ability to form the short stem was abrogated constitutively expressed the $m g t A$ gene (i.e., no longer responded to $\mathrm{Mg}^{2+}$ ). It appears that the short stem and not the particular sequences that make up the stem is the critical element in $\mathrm{Mg}^{2+}$ sensing because making the compensatory mutations to restore formation of the short stem brought back $\mathrm{Mg}^{2+}$-regulated expression of the $m g t A$ gene. That stem-loop A may be involved in $\mathrm{Mg}^{2+}$ sensing is further supported by the $\mathrm{Mg}^{2+}$-promoted changes in the stem-loop A structure when present by itself (Cromie et al. 2006).

The requirement for sequences in loop $\mathrm{A}$ for $\mathrm{Mg}^{2+}$ sensing does not mean that $\mathrm{Mg}^{2+}$ binding to this region is sufficient to trigger the conformational changes that affect $m g t A$ expression. Therefore, although it is possible that loop A may constitute a $\mathrm{Mg}^{2+}$-binding pocket analogous to those involved in metabolite-sensing riboswitches (Serganov et al. 2004, 2006; Montange and Batey 2006), we cannot rule out the possibility of $\mathrm{Mg}^{2+}$ affecting the formation of the various stem-loop structures by binding to multiple sites in the $5^{\prime} \mathrm{UTR}$. In this context, it is important to note that in addition to stem-loops A, B, and C, several regions of the Salmonella mgtA 5'UTR show high levels of sequence identity with homologs in other species (Fig. 1A). These regions could also be involved in $\mathrm{Mg}^{2+}$ sensing. Alternatively or in addition, they may be conserved due to their role in regulating $m g t A$ expression.

\section{How the $\mathrm{Mg}^{2+}$-responding Riboswitch May Control Expression of the MgtA Protein}

We could recapitulate the $\mathrm{Mg}^{2+}$-regulated transcription elongation beyond the $m g t A 5^{\prime} \mathrm{UTR}$ region using an in vitro transcription system consisting of the $E$. coli RNA polymerase $\sigma^{70}$ holoenzyme, linear DNA templates harboring a derivative of the lac promoter (Liu et al. 2004), and different concentrations of $\mathrm{Mg}^{2+}$ around the 
physiological levels (Froschauer et al. 2004). A template harboring the full-length wild-type $5^{\prime} \mathrm{UTR}$ of the $m g t A$ gene behind the lac promoter derivative gave rise to two bands: a large band representing the readthrough transcript, the amount of which decreased as the $\mathrm{Mg}^{2+}$ concentration increased, and a small band corresponding to a truncated product of approximately 220 nucleotides. These in vitro experiments demonstrated that the $\mathrm{Mg}^{2+}$ regulated expression mediated by the $5^{\prime} \mathrm{UTR}$ of the $m g t A$ gene does not require proteins other than RNA polymerase, and they are consistent with the notion that the $5^{\prime} \mathrm{UTR}$ is a $\mathrm{Mg}^{2+}$-responding regulatory element. Yet, it is possible that a protein may participate in the regulation of $m g t A$ elongation in vivo.

There are (at least) three possible mechanisms that may explain why the $m g t A$ transcript does not go beyond a certain position within the $5^{\prime} \mathrm{UTR}$ when bacteria experience $\mathrm{Mg}^{2+}$ levels that are not too low. On the one hand, the truncated product could result from RNAmediated cleavage as demonstrated for the glucosamine6-phosphate-responding riboswitch (Winkler et al. 2004). On the other hand, the truncated product may originate as the result of early transcription termination or due to RNA polymerase pausing at a site and then falling off the DNA template. The $m g t A 5^{\prime}$ UTR does not appear to function as a ribozyme because (1) the truncated product could be labeled using ${ }^{32} \mathrm{pCp}$ and T4 RNA ligase, (2) ribozymes that yield free $2^{\prime}$ and $3^{\prime}$ hydroxyl groups are typically larger than the 220-nucleotide mgtA $5^{\prime}$ UTR (Jacquier 1996), (3) there was no delay in the appearance of the truncated product relative to the readthrough product as one might expect for a maturation reaction, and (4) addition of $\mathrm{Mg}^{2+}$ did not promote degradation of the readthrough transcript generated in vitro. Moreover, when the 5'UTR was synthesized in vitro by T7 RNA polymerase, only a single product was of the same size as that corresponding to the readthrough transcript generated with $E$. coli RNA polymerase. (The caveat with the latter result is that T7 RNA polymerase-promoted transcription of the mgtA templates may be too fast for the hypothetical structure having the putative ribozyme activity to form.)

Transcription attenuation mechanisms have been typically associated with the formation of transcription terminators in one of the alternative structures. However, the sequences preceding nucleotide 220 lack the typical features of Rho-independent terminators (i.e., a GC-rich RNA hairpin followed by a poly(U) sequence [Landick et al. 1996]), and the generation of a truncated product in the in vitro transcription reaction did not require the Rho protein. This raises the possibility that the truncated product may be formed as a consequence of transcription pausing followed by RNA polymerase release from the DNA template. Although more experiments are required to determine how $\mathrm{Mg}^{2+}$ affects transcription elongation in the $m g t A 5^{\prime} \mathrm{UTR}$, sequences beyond those corresponding to stem-loops A, B, and C appear to participate in this process because a strain harboring a derivative of the $5^{\prime} \mathrm{UTR}$ with the sequence corresponding to positions 1-178 (which does not include sequences beyond stem-loop B) exhibited constitutive $m g t A$ expression.

\section{A Physiological Rationale for Dual Control of $m g t A$ Expression}

When Salmonella experiences a low $\mathrm{Mg}^{2+}$ environment, $m g t A$ is the first PhoP-activated gene that is transcribed (our unpublished results), which may reflect the organism's effort to maintain physiological levels of cytoplasmic $\mathrm{Mg}^{2+}$. Once the MgtA protein is produced, it will mediate internalization of $\mathrm{Mg}^{2+}$, which will eventually bind to the $m g t A 5^{\prime} \mathrm{UTR}$ to shut off MgtA expression (Fig. 2). This regulatory design allows the rapid uptake of $\mathrm{Mg}^{2+}$ and at the same time makes MgtA an arbiter of its own expression.

The $m g t A$ gene is controlled at the level of transcription initiation by the PhoP protein, which is activated in response to the extracytoplasmic levels of $\mathrm{Mg}^{2+}$ sensed by the PhoQ protein, and at the level of transcription elongation in response to the cytoplasmic levels of $\mathrm{Mg}^{2+}$ sensed by the $m g t A 5^{\prime} \mathrm{UTR}$. Thus, $\mathrm{Mg}^{2+}$ acts in two different compartments to control different steps in $m g t A$ transcription. This dual control of the $m g t A$ gene is in contrast to most genes regulated by riboswitches, which are not subjected to regulation at the level of transcription initiation (Winkler and Breaker 2003; Brantl 2004; Nudler and Mironov 2004). The dual regulation of $m g t A$ expression is somewhat reminiscent of that governing expression of the $\operatorname{tr} p$ biosynthetic genes of E. coli. In this case, the control is exerted both by the tryptophanresponding TrpR protein, a transcriptional repressor that binds to the trp promoter-operator region, and by a transcription attenuation mechanism that responds to charged tRNA ${ }^{\text {Trp }}$ (Bennett and Yanofsky 1978; Yanofsky 2004). As described for the regulation of trp, most of the $m g t A$ regulation takes place at the level of transcription initiation (i.e., by TrpR and PhoP), and only a small fraction is controlled at the level of transcription elongation (by the leader sequence and riboswitch, respectively).

What is the purpose of the dual $m g t A$ control? It may enable Salmonella to exert differential regulation over those determinants directly affecting cytoplasmic $\mathrm{Mg}^{2+}$ (i.e., the $\mathrm{Mg}^{2+}$ transporters MgtA and MgtB and potentially other proteins) from those mediating modifications in the bacterial cell envelope (i.e., the proteins affecting the negative charges in the LPS) when they are all under transcriptional control of the same regulatory system (i.e., PhoP/PhoQ) (Groisman 2001). Indeed, expression of the PhoP-regulated $m g t C B$ operon, which encodes the inner membrane protein $\mathrm{MgtC}$ and the $\mathrm{Mg}^{2+}$ transporter MgtB, appears to have features in common with those controlling the $m g t A$ gene because $m g t C B$ transcription also responds to $\mathrm{Mg}^{2+}$ in a strain lacking the $\mathrm{Mg}^{2+}$ sensor PhoQ protein in a process that requires the $5^{\prime}$ UTR preceding the $m g t C$ open reading frame (our unpublished results).

\section{Does the $\boldsymbol{m g t} \boldsymbol{A}$-derived 5'UTR Regulate Gene Expression by Affecting Other mRNAs in trans?}

The Storz laboratory has demonstrated that an RNA fragment corresponding to the $5^{\prime} \mathrm{UTR}$ of the $m g t A$ transcript accumulates in E. coli grown in LB media and that 


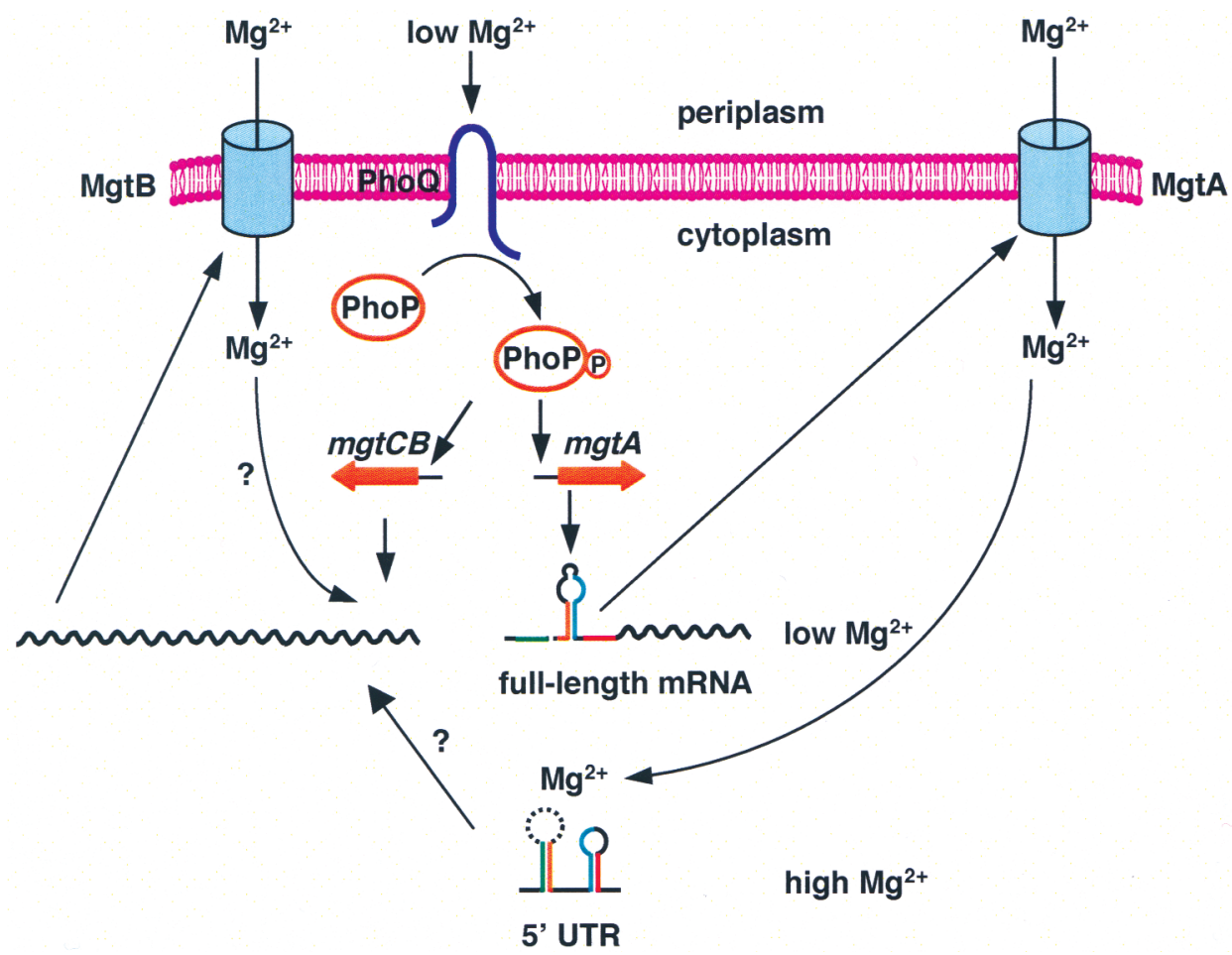

Figure 2. Model for regulation of the Salmonella $\mathrm{MgtA} \mathrm{Mg}^{2+}$ transporter. When Salmonella experiences a low $\mathrm{Mg}^{2+}$ environment, the sensor PhoQ responds to extracytoplasmic $\mathrm{Mg}^{2+}$ by promoting phosphorylation of the DNA-binding protein PhoP, which binds to the $m g t A$ promoter and initiates $m g t A$ transcription. If cytoplasmic $\mathrm{Mg}^{2+}$ levels are above a certain threshold, $\mathrm{Mg}^{2+}$ binding to the $m g t A 5^{\prime}$ UTR results in the formation of stem-loop structures that promote transcription stopping within the $5^{\prime}$ UTR. Once the cytoplasmic $\mathrm{Mg}^{2+}$ concentration goes below a certain level, an alternative stem-loop structure is formed, which allows readthrough into the $m g t A$-coding region. Production of the MgtA protein allows internalization of $\mathrm{Mg}^{2+}$, the concentration of which will increase resulting in binding to the $m g t A 5^{\prime} \mathrm{UTR}$ and shutting off of MgtA expression. The $\mathrm{MgtB} \mathrm{Mg}^{2+}$ transporter is also regulated by $\mathrm{Mg}^{2+}$ in a process that requires the $5^{\prime}$ UTR region preceding the $m g t C$ gene. That $5^{\prime}$ UTR region could be an $\mathrm{Mg}^{2+}$ sensor or it may be the target of the truncated RNA corresponding to the 220-nucleotide fragment originating from the mgtA 5'UTR. (Modified, with permission, from Cromie et al. 2006 [C Elsevier].)

the levels of this small RNA are lower in a strain harboring a mutation in the $h f q$ gene (Kawano et al. 2005), which encodes a protein shown to bind to bacterial small RNAs exerting regulatory effects in trans. When we consider the fact that $m g t A$ has the highest affinity of the PhoP-activated promoters (Minagawa et al. 2003) and it is the first and most highly expressed gene when the PhoP/PhoQ system is activated (our unpublished results), this raises the possibility that the $m g t A 5^{\prime} \mathrm{UTR}$ might act in trans to regulate gene expression. The putative target mRNAs of the $m g t A 5^{\prime} \mathrm{UTR}$ should be produced concurrently with the $m g t A 5^{\prime} \mathrm{UTR}$ gene, and thus they are likely to be members of the PhoP regulon, but they could also be genes that are constitutively expressed. Therefore, we examined the DNA sequence between the reported transcription start site and the predicted site of translation initiation for several members of the PhoP regulon. We found that in addition to the 5 'UTR of the $m g t C B$ operon discussed above, several PhoP-activated genes harbor 5'UTRs that are more than 200 nucleotides long (i.e., $\operatorname{pagC}, \operatorname{nagA}$, and $u g t L$; Table 1). Moreover, we could identify regions of complementarity between the mgtA 5'UTR and the 5'UTRs of these genes. This suggests that the $m g t A 5^{\prime} \mathrm{UTR}$ may have two roles: First, it may act as an $\mathrm{Mg}^{2+}$-responding riboswitch that determines whether the mgtA-coding region is transcribed resulting in the production of the MgtA protein. Second, it may regulate expression of other genes by acting in trans. Alternatively, the PhoPregulated genes with unusually long 5'UTRs may respond to $\mathrm{Mg}^{2+}$ or other ligands to alter expression of the corresponding open reading frame (Fig. 2).

\section{CONCLUSIONS}

The 5'UTR of the mgtA gene constitutes the first example of a cation-responsive riboswitch. However, bioinformatics studies suggest that there are likely to be other cation-responding riboswitches (Barrick et al.

Table 1. PhoP-regulated Genes with Long $5^{\prime}$ UTRs

\begin{tabular}{|c|c|c|}
\hline Gene & $\begin{array}{l}\text { Size of 5'UTR } \\
\text { (in nucleotides) }\end{array}$ & $\begin{array}{l}\text { Function of } \\
\text { gene product }\end{array}$ \\
\hline$\overline{m g t C B}$ & 281 & $\begin{array}{l}\mathrm{Mg}^{2+} \text { transport, } \\
\text { growth in low } \mathrm{Mg}^{2+}\end{array}$ \\
\hline $\operatorname{nag} A$ & 417 & $\begin{array}{l}N \text {-acetylglucosamine } \\
\text { deacetylase }\end{array}$ \\
\hline $\operatorname{pag} C$ & 559 & outer-membrane protein \\
\hline$u g t L$ & 192 & lipid-A phosphatase? \\
\hline
\end{tabular}


2004; Merino and Yanofsky 2005). This regulation of the $\mathrm{Mg}^{2+}$ transporter MgtA protein may enable Salmonella to exert differential control over those genes that are involved in cytoplasmic $\mathrm{Mg}^{2+}$ homeostasis from those involved in the modification of $\mathrm{Mg}^{2+}$-binding sites in the cell envelope. Moreover, by regulating $\mathrm{Mg}^{2+}$ transport, MgtA may impact other riboswitches that respond to other ligands but are affected by $\mathrm{Mg}^{2+}$ (Yamauchi et al. 2005). The truncated mgtA RNA derived from the $5^{\prime}$ UTR when organisms experience high $\mathrm{Mg}^{2+}$ might have the additional property of regulating genes in trans.

\section{ACKNOWLEDGMENTS}

Part of the research described in this paper was supported by grant AI49561 from the National Institutes of Health to E.A.G., who is an Investigator of the Howard Hughes Medical Institute.

\section{REFERENCES}

Barrick J.E., Corbino K.A., Winkler W.C., Nahvi A., Mandal M., Collins J., Lee M., Roth A., Sudarsan N., Jona I., et al. 2004. New RNA motifs suggest an expanded scope for riboswitches in bacterial genetic control. Proc. Natl. Acad. Sci. 101: 6421.

Bennett G.N. and Yanofsky C. 1978. Sequence analysis of operator constitutive mutants of the tryptophan operon of Escherichia coli. J. Mol. Biol. 121: 179.

Blanc-Potard A.B. and Groisman E.A. 1997. The Salmonella selC locus contains a pathogenicity island mediating intramacrophage survival. EMBO J. 16: 5376.

Brantl S. 2004. Bacterial gene regulation: From transcription attenuation to riboswitches and ribozymes. Trends Microbiol. 12: 473.

Castelli M.E., García Véscovi E.G., and Soncini F.C. 2000. The phosphatases activity is the target for $\mathrm{Mg}^{2+}$ regulation of the sensor protein PhoQ in Salmonella. J. Biol. Chem. 275: 22948.

Chamnongpol S. and Groisman E.A. 2000. Acetyl-phosphatedependent activation of a mutant $\mathrm{PhoP}$ response regulator that functions independently of its cognate sensor kinase. J. Mol. Biol. 300: 291.

2002. $\mathrm{Mg}^{2+}$ homeostasis and avoidance of metal toxicity. Mol. Microbiol. 44: 561.

Chamnongpol S., Cromie M., and Groisman E.A. 2003. $\mathrm{Mg}^{2+}$ sensing by the $\mathrm{Mg}^{2+}$ sensor PhoQ of Salmonella enterica. J. Mol. Biol. 325: 795 .

Cromie M.J., Shi Y., Latifi T., and Groisman E.A. 2006. An RNA sensor for intracellular $\mathrm{Mg}^{2+}$. Cell 125: 71.

Froschauer E.M., Kolisek M., Dieterich F., Schweigel M., and Schweyen R.J. 2004. Fluorescence measurements of free $\left[\mathrm{Mg}^{2+}\right]$ by use of mag-fura 2 in Salmonella enterica. FEMS Microbiol. Lett. 237: 49.

Groisman E.A. 2001. The pleiotropic two-component regulatory system PhoP-PhoQ. J. Bacteriol. 183: 1835.

Groisman E.A., Kayser J., and Soncini F.C. 1997. Regulation of polymyxin resistance and adaptation to low- $\mathrm{Mg}^{2+}$ environments. J. Bacteriol. 179: 7040.

Hanna R. and Doudna J.A. 2000. Metal ions in ribozyme folding and catalysis. Curr. Opin. Chem. Biol. 4: 166.

Henkin T.M. and Yanofsky C. 2002. Regulation by transcription attenuation in bacteria: How RNA provides instructions for transcription termination/antitermination decisions. Bioessays 24: 700.

Jacquier A. 1996. Group II introns: Elaborate ribozymes. Biochimie 78: 474.
Kawano M., Reynolds A.A., Miranda-Rios J., and Storz G. 2005. Detection of 5'- and 3'-UTR-derived small RNAs and cis-encoded antisense RNAs in Escherichia coli. Nucleic Acids Res. 33: 1040.

Kim D.S., Gusti V., Pillai S.G., and Gaur R.K. 2005. An artificial riboswitch for controlling pre-mRNA splicing. $R N A$ 11: 1667.

Landick R., Turnbough C.L., and Yanofsky C. 1996. Transcription attenuation. In Escherichia coli and Salmonella: Cellular and molecular biology (ed. F.C. Neidhardt et al.), p. 1263. ASM Press, Washington, D.C.

Liu M., Tolstorukov M., Zhurkin V., Garges S., and Adhya S. 2004. A mutant spacer sequence between -35 and -10 elements makes the $\mathrm{P}_{\text {lac }}$ promoter hyperactive and cAMP receptor protein-independent. Proc. Natl. Acad. Sci. 101: 6911.

Maguire M.E. 2006. Magnesium transporters: Properties, regulation and structure. Front. Biosci. 11: 3149.

Merino E. and Yanofsky C. 2005. Transcription attenuation: A highly conserved regulatory strategy used by bacteria. Trends Genet. 21: 260.

Minagawa S., Ogasawara H., Kato A., Yamamoto K., Eguchi Y., Oshima T., Mori H., Ishihama A., and Utsumi R. 2003. Identification and molecular characterization of the $\mathrm{Mg}^{2+}$ stimulon of Escherichia coli. J. Bacteriol. 185: 3696.

Montagne M., Martel A., and Le Moual H. 2001. Characterization of the catalytic activities of the PhoQ histidine protein kinase of Salmonella enterica serovar Typhimurium. J. Bacteriol. 183: 1787.

Montange R.K. and Batey R.T. 2006. Structure of the S-adenosylmethionine riboswitch regulatory mRNA element. Nature 441: 1172.

Muller M., Weigand J.E., Weichenrieder O., and Suess B. 2006. Thermodynamic characterization of an engineered tetracyclinebinding riboswitch. Nucleic Acids Res. 34: 2607.

Nudler E. and Mironov A.S. 2004. The riboswitch control of bacterial metabolism. Trends Biochem. Sci. 29: 11.

Reinhart R.A. 1988. Magnesium metabolism. A review with special reference to the relationship between intracellular content and serum levels. Arch. Intern. Med. 148: 2415.

Serganov A., Polonskaia A., Phan A.T., Breaker R.R., and Patel D.J. 2006. Structural basis for gene regulation by a thiamine pyrophosphate-sensing riboswitch. Nature 441: 1167.

Serganov A., Yuan Y.R., Pikovskaya O., Polonskaia A., Malinina L., Phan A.T., Hobartner C., Micura R., Breaker R.R., and Patel D.J. 2004. Structural basis for discriminative regulation of gene expression by adenine- and guaninesensing RNAs. Chem. Biol. 11: 1729.

Smith R.L. and Maguire M.E. 1995. Distribution of the CorA $\mathrm{Mg}^{2+}$ transport system in gram-negative bacteria. J. Bacteriol. 177: 1638.

177. 1998. Microbial magnesium transport: Unusual transporters searching for identity. Mol. Microbiol. 28: 217.

Soncini F.C., Garcia Vescovi E., Solomon F., and Groisman E.A. 1996. Molecular basis of the magnesium deprivation response in Salmonella typhimurium: Identification of PhoPregulated genes. J. Bacteriol. 178: 5092.

Tao T., Grulich P.F., Kucharski L.M., Smith R.L., and Maguire M.E. 1998. Magnesium transport in Salmonella typhimurium: Biphasic magnesium and time dependence of the transcription of the $m g t A$ and $m g t C B$ loci. Microbiology 144: 655 .

Winkler W.C. 2005. Riboswitches and the role of noncoding RNAs in bacterial metabolic control. Curr. Opin. Chem. Biol. 9: 594.

Winkler W.C. and Breaker R.R. 2003. Genetic control by metabolite-binding riboswitches. Chembiochem. 4: 1024.

. 2005. Regulation of bacterial gene expression by riboswitches. Annu. Rev. Microbiol. 59: 487.

Winkler W.C., Nahvi A., Roth A., Collins J.A., and Breaker R.R. 2004. Control of gene expression by a natural metaboliteresponsive ribozyme. Nature 428: 281. 


\section{GROISMAN ET AL.}

Yamamoto K., Ogasawara H., Fujita N., Utsumi R., and Ishihama A. 2002. Novel mode of transcription regulation of divergently overlapping promoters by PhoP, the regulator of two-component system sensing external magnesium availability. Mol. Microbiol. 45: 423.

Yamauchi T., Miyoshi D., Kubodera T., Nishimura A., Nakai S., and Sugimoto N. 2005. Roles of $\mathrm{Mg}^{2+}$ in TPP-dependent riboswitch. FEBS Lett. 579: 2583.
Yanofsky C. 2004. The different roles of tryptophan transfer RNA in regulating trp operon expression in $E$. coli versus B. subtilis. Trends Genet. 20: 367.

Zwir I., Shin D., Kato A., Nishino K., Latifi T., Solomon F., Hare J.M., Huang H., and Groisman E.A. 2005. Dissecting the PhoP regulatory network of Escherichia coli and Salmonella enterica. Proc. Natl. Acad. Sci. 102: 2862. 


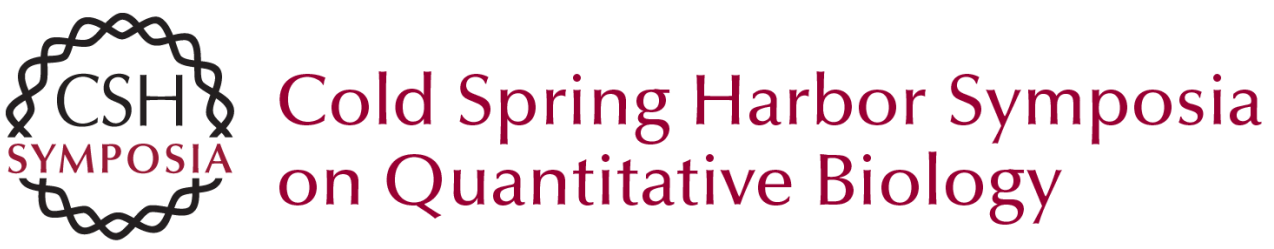

\title{
A $\mathrm{Mg}^{2+}$-responding RNA That Controls the Expression of a $\mathrm{Mg}^{2+}$ Transporter
}

\author{
E.A. GROISMAN, M.J. CROMIE, Y. SHI, et al.
}

Cold Spring Harb Symp Quant Biol 2006 71: 251-258

Access the most recent version at doi:10.1101/sqb.2006.71.005

References This article cites 40 articles, 12 of which can be accessed free at: http://symposium.cshlp.org/content/71/251.full.html\#ref-list-1

\section{License}

Email Alerting

Receive free email alerts when new articles cite this article - sign up in Service the box at the top right corner of the article or click here. 